\title{
A medida do decidir: atuação do STF nos processos de demarcação territorial pós-julgamento da Terra Indígena Raposa Serra do Sol
}

\section{The extent of decide: The performance of the STF in territorial demarcation processes post-judgment of the Raposa Serra do Sol}

Anabelle Santos Lages - Doutora em Sociologia. Bolsista PNPD do Programa de PósGraduação em Sociologia da Universidade Federal de Alagoas. E-mail: anabellelages@ yahoo.com.br

Wendell Ficher Teixeira Assis - Doutor em Planejamento Urbano e Regional. Professor Adjunto do Instituto de Ciências Sociais da Universidade Federal de Alagoas. E-mail: wwficher@yahoo.com.br

\section{Resumo}

O artigo analisa os desdobramentos sociopolíticos e jurídicos decorrentes da decisão do STF sobre a demarcação da Terra Indígena Raposa Serra do Sol, sobretudo, no que tange às disputas políticas para ampliar a abrangências das dezenove condicionantes formuladas no âmbito do julgamento. Para tanto, expõe as estratégias mobilizadas pelas populações indígenas na tentativa de sensibilizar a opinião pública, ao mesmo tempo em que procuram influir na decisão dos Ministros do Supremo. De maneira complementar, o trabalho escrutina os debates no âmbito do STF que compuseram o julgamento sobre a demarcação de duas terras indígenas que ocorreram pós-decisão do caso Raposa, a saber; Terra Indígena Porquinhos dos Canelas e Terra Indígena Guyraroka. A partir da análise comparativa, pode-se indicar que longe de uma neutralidade jurídica inerente ao ato de decidir, estão em jogo tanto um intricado uso dos instrumentos do direito, como a capacidade de incidência e pressão política levadas a cabo pelas populações indígenas.

\section{Palavras-chave}

Demarcação; Supremo Tribunal Federal; Terra Indígena; Raposa Serra do Sol.

\begin{abstract}
The article analyzes the socio-political and legal developments arising from the decision of the Supreme Court on the demarcation of the Raposa Serra do Sol, especially when it comes to political disputes to expand the scopes of the nineteen conditions formulated under the trial. Therefore, it exposes the strategies deployed by the indigenous populations in an effort to raise public awareness, while seeking to influence the decision of the Ministers of the Supreme. In a complementary way, the work scrutinizes the debates that made up the decision on the demarcation of two indigenous lands, namely; Indigenous Land of Porquinho dos Canelas and Indigenous Land Guyraroka. From the comparative analysis, it can be stated that far from legal neutrality inherent in the act of deciding, are at stake both an intricate use of the right tools, such as the incidence capacity and political pressure carried out by indigenous peoples.
\end{abstract}

\section{Keywords}

Demarcation; Federal Supreme Court; Indigenous Land; Raposa Serra do Sol. 


\section{INTRODUÇÃO}

No dia 19 de março de 2009 o Supremo Tribunal Federal - STF declarou constitucional o modelo contínuo da demarcação da Terra Indígena Raposa Serra do Sol, derrubando a liminar que garantia a presença dos não índios na região. A decisão pode ser considerada jurídica, sociológica e politicamente emblemática. Do ponto de vista jurídico, desde o caso Krenak, em 1993, o STF não julgava o mérito de uma ação demarcatória indígena. Até então as decisões se restringiam a questões processuais (YAMADA, 2010), isto é, sequer adentravam na discussão sobre o direito dos indígenas à posse de determinado território.

Do ponto de vista sociológico, o valor analítico do caso se referenda nos debates decorrentes da decisão. Para citar alguns exemplos, pode-se dizer da sempre presente problemática da disputa fundiária no Brasil, dos discursos que advogam a integração do índio à sociedade (ao mesmo tempo em que lhe retira direitos exatamente pelo fato de considerá-lo integrado), dos questionamentos sobre a recente e midiática evidência dos ministros do STF, dando à sociedade mais uma oportunidade para interrogar sobre a figura desses que são os últimos intérpretes da lei, autorizados a decidir sobre os valores sociais em vigência (REPOLÊS, 2003).

No plano político imediato, a demarcação da Terra Indígena Raposa Serra do Sol foi um compromisso de campanha do Presidente Luis Inácio Lula da Silva nas eleições presidenciais de $2002^{1}$. Apontada como uma das "situações graves que afetam populações indígenas, configurando flagrante desrespeito aos direitos humanos" (COMPROMISSO COM OS POVOS INDÍGENAS DO BRASIL, 2002, p.9), a homologação da Terra Indígena Raposa Serra do Sol foi apresentada como uma medida primordial da futura administração. No documento, elaborado com a participação de diversas lideranças, a política indigenista do governo Fernando Henrique Cardoso foi apresentada como lamentável, em razão das precárias condições de funcionamento da FUNAI, bem como a demora para a criação de um novo Estatuto das Sociedades Indígenas.

Além disso, a repercussão internacional dos mais de trinta anos de lutas por reconhecimento e violências sofridas pelas comunidades da Terra Indígena Raposa Serra do Sol certamente ajudou a formar o convencimento de que seria interessante mostrar para o mundo que o Brasil não era o país "que pior tratava seus índios", como era dito de tempos em tempos, retirando da opinião internacional a impressão de que o Brasil era um país bárbaro (LIMA, 1995). O fato, como

As expectativas em relação ao governo Lula restaram frustradas no que se referiu à demarcação de terras indígenas. A própria homologação da TIRSS só veio a ocorrer em 2005, mas, com o processo judicial, só foi formalmente concluída em 2009, com a decisão do Supremo. 
argumentou Silva (2009, p. 153), à época do julgamento, é que estava “em jogo não apenas uma pendenga entre índios e não-índios na sociedade de Roraima, [mas estavam] na berlinda todos os brasileiros, em sua capacidade de proteger, pelas mãos do Estado, a preciosa esfera dos valores culturais e imateriais da nação".

Pelo exposto, não parece demais inferir que a atmosfera ao redor do julgamento tinha ares de imprescindibilidade de uma decisão favorável aos indígenas. Além do direito propriamente dito, sua legitimidade sociopolítica resultava da conjugação de particularidades como o tempo de luta pela causa, forte pressão internacional e um movimento indígena profundamente articulado e organizado. Juntos, todos esses elementos culminaram num fato político capaz de corroborar a afirmação de Lassalle (2001), que afirma a insustentabilidade das regras constitucionais quando a arena política não fornece o necessário suporte à sua aplicabilidade. De acordo com essa perspectiva, no limite, os próprios fundamentos da democracia e do estado de direito necessitam desse aporte político para se materializarem de fato (WEINGAST, 1997). Da Ros (2007) sintetiza, afirmando que as "regras são cumpridas porque há interesse dos demais agentes da arena política em observá-las - especialmente daqueles atores capazes de intervir no sentido de modificar essas mesmas regras".

Após seis anos do reconhecimento da legalidade da demarcação contínua da terra Indígena Raposa Serra do Sol, arrefecido o debate midiático, algumas considerações sobre os desdobramentos jurisprudenciais daquele julgamento já podem ser feitos com maior clareza. Por essa razão, neste artigo, nosso olhar se dirigirá às respostas dadas pelo Supremo aos casos posteriores ao da Raposa Serra do Sol. O objetivo é compreender se a afirmação de Lassale (2001) sobre a aplicabilidade das normas constitucionais (aqui entendido como reconhecimento de direitos) dependeria mesmo de um ambiente disposto a receber determinada decisão. A esse entender, as análises de algumas decisões tendem a concordar com Carrió (1986), quando afirma que, a despeito dos Tribunais serem compreendidos como a instância garantidora dos direitos das minorias os casos concretos não validam essa apresentação. Ao contrário, sua atuação contramajoritária restaria facilitada quando não mais existissem maiorias adversárias na arena política. A constatação faz surgir um questionamento que, percebemos, tem estado presente nos recentes estudos sobre os Tribunais Superiores (WERNECK VIANNA et al., 1999; VIEIRA, 2002), não apenas o brasileiro, mas que aqui poderia ser expressa da seguinte maneira: seria o Supremo Tribunal Federal um ente organicamente político?

Dito isso, convém apresentar a dinâmica norteadora deste trabalho. Primeiro, a análise ponderará sobre a relevância de contextos extraconstitucionais para a formação de sensibilidades que orientam as decisões judiciais. Nesse 
sentido, nos limites destas linhas, será feito um apanhado das circunstâncias históricas que forneceram os elementos político-simbólicos que atravessaram todo o arranjo jurídico e discursivo presente no acórdão proferido na demarcação da Terra Indígena Raposa Serra do Sol. Em seguida, serão abordados dois litígios sobre demarcação levados ao Supremo após 2009: o caso da Terra Indígena Porquinhos dos Canelas - Apãnjekra, localizada no Estado do Maranhão² e o caso da Terra Indígena Guyraroka, pertencente à etnia Guarani Kaiowá3 situada em área do Estado do Mato Grosso do Sul.

Em tempo, vale destacar que a perspectiva analítica do artigo se ancora em uma abordagem interdisciplinar que realçando o diálogo entre o direito e as ciências sociais procurará fazer emergir uma melhor compreensão dos fundamentos argumentativos que balizam as decisões do STF, mormente, no que tange às demarcação de terras indígenas que ocorreram após o emblemático caso da Terra Indígena Raposa Serra do Sol.

\section{OS ACESSÓRIOS SEGUEM O PRINCIPAL: A DECISÃO DA RAPOSA SERRA DO SOL E DOIS CASOS SUBSEQUENTES}

Ao longo do debate que circundou a tomada de decisão dos Ministros do Supremo no caso da demarcação da Terra Indígena Raposa Serra do Sol, seu aspecto modelar foi exaltado quase que de forma absoluta. Espécie de regramento geral utilizado para balizar as futuras demarcações e decisões judiciais sobre a matéria, "deixando fundadas as bases jurídicas para o contínuo reconhecimento aos povos indígenas das terras que tradicionalmente ocupam" (BRASIL, 2008, p. 760). Para compreender essa ambição jurisprudencial, quase normativa, dos Ministros faz-se necessário desviar o olhar das quase oitocentas páginas do processo e redirecioná-lo senão para a inteireza de sua história, mas para os pontos que lhe legaram o nem sempre definível predicativo de paradigmático.

Localizada na porção nordeste do estado de Roraima, a Terra Indígena Raposa Serra do Sol possui área de 1.743,089 hectares e pertence à chamada Amazônia brasileira, composta pelos estados do Amazonas, Acre, Amapá, Pará, Rondônia, Roraima e Tocantins (BRASIL, 2008). Um dos argumentos levantados pelos oponentes da demarcação contínua dizia respeito ao que se poderia chamar de mito da faixa de fronteira, uma vez que a terra indígena encontra-se na tríplice fronteira entre Brasil, Venezuela e República Cooperativista da Guiana. As disputas envolvendo terras amazônicas são carregadas de estratégias que visam a

\footnotetext{
Recurso ordinário em mandado de segurança 29.542, de 30 de setembro de 2014.

Recurso ordinário em mandado de segurança 29.087, de 19 de abril de 2014.
} 
deslegitimação de direitos. A despeito de serem refutadas antropológica elegalmente, as reclamações levadas ao STF possuem certa capilaridade entre a população leiga. Assim, dependendo da situação apresentada, um ou outro argumento costuma ser vivificado por aqueles que são contrários à demarcação pretendida.

O processo de reconhecimento da Terra Indígena Raposa Serra do Sol teve início em 1917, quando foram estabelecidas algumas práticas de governo que visavam à demarcação. Naquele ano, o governo do estado do Amazonas editou a lei estadual n. 941, que destinava as terras que se localizavam entre os rios Surumu e Contigo aos índios Macuxi e Jaricuna. Em 1919, o Serviço de Proteção aos Índios dá início ao processo de demarcação da área tendo em vista as constantes invasões de fazendeiros. A contradição reside no fato de que a ampliação e/ou criação de fazendas, inclusive por meio de doações de terras, era uma política do governo federal para incentivar a ocupação do Território e fazia parte de um projeto migratório para a região, existente desde os tempos coloniais, em função da considerada baixa densidade demográfica. A chamada colonização pela "pata do boi" fazia parte desse processo de avanço sobre os territórios indígenas, com a ampliação das fazendas na proporção do aumento do rebanho bovino (COSTA SILVA, 2012). Expedido em 1925, o título de concessão dessas terras não reverberou entre as autoridades locais; a demarcação iniciada pelo SPI não foi finalizada (CARVALHO; MAIOR, 2008).

Após idas e vindas, avanços e retrocessos, o processo de demarcação da Terra Indígena Raposa Serra do Sol foi concluído no primeiro semestre de 2005. No dia 20 de maio de 2005, foi ajuizada Ação Popular (Petição 3388/RR) em desfavor da União. Os autores da ação foram os então senadores da República Augusto Affonso Botelho Neto e Francisco Mozarildo de Melo Cavalcanti (Arena, PFL, DEM). Os autores populares pediam a declaração de nulidade da Portaria 534/2005, emitida pelo Ministro de Estado da Justiça, bem como do Decreto do Presidente da República. Daquele ano em diante, "inicia-se então a mais importante batalha jurídica pelos direitos indígenas desde a redemocratização do Brasil" (DUARTE DO PATEO, 2009, p. 166); o caso da demarcação da Terra Indígena Raposa Serra do Sol foi ganhando cada vez mais destaque na imprensa brasileira. Manobras judiciais que pretendiam reverter a homologação das terras e discursos inflamados sobre os riscos à segurança nacional e ao desenvolvimento do país eram continuamente intercalados por atos de violência física praticados principalmente pelos partidários da demarcação em ilhas.

Tão logo a ação foi impetrada, o Conselho Indigenista de Roraima iniciou uma forte campanha nacional e internacional a favor da demarcação contínua. No âmbito interno, um dos alvos foi o próprio órgão responsável por proferir a 
decisão. Assim, ao longo dos quase quatro anos de duração do processo, foram solicitadas audiências com os ministros do STF pelos representantes indígenas, com o intuito de defender a demarcação nos moldes como havia sido realizada. Essa estratégia de sensibilização da opinião pública e de pressão política sobre o Supremo pode ser desprendida do fragmento de entrevista ${ }^{4}$ disposto a seguir no qual uma liderança Wapichana discorre sobre as estratégias de luta política levada a cabo pelas populações indígenas durante o processo de julgamento da demarcação;

[...] a gente queria chamar a atenção do mundo para o julgamento do STF. Da imprensa principalmente, a gente queria chamar a atenção da imprensa, para saber o que ia passar, né? Nós conseguimos atingir nosso objetivo, porque ao mesmo tempo que a gente estava fazendo essa campanha na Europa, aqui as lideranças estavam em Brasília e as comunidades estavam mobilizadas aqui. Foi uma rede que nós criamos para chamar a atenção. Essa campanha teve como objetivo levar lideranças para conversar com os ministros do STF. Nós fomos várias vezes conversar com os ministros para colocar também a nossa versão. Levando vídeos, fotos, mapas, demonstrando como era nossa vida dentro da terra para mostrar a importância das terras contínuas. [...] Cada vez ia uma comitiva falar com os ministros, né? Como é um trabalho coletivo, chegava e dizia, olha, ele é assim, assim, assim. Então, assim, já dava para saber quem era quem, quem eram os ministros mais favoráveis, quem tinha mais resistência. Eles até recebiam, mas tinham uns que não queriam ouvir muito. Eles ouviram assim... Claro que alguns receberam por mais tempo, assim como [teve] ministro que recebeu a documentação no corredor. E a gente já entendia porque que era aquele recebimento no corredor. (Entrevista com liderança indígena Wapichana, Boa Vista-RR, julho de 2012).

As estratégias de atuação do Conselho Indigenista de Roraima - CIR, ${ }^{5}$ desenvolvidas para a obtenção de um julgamento favorável à demarcação contínua, mostram que conhecer a dinâmica do campo jurídico (BOURDIEU, 1989), sobretudo sua porosidade, apresenta-se fundamental para colocar em prática a observação de Arendt (1979) de que o direito não é dado, mas construído. Os pedidos de audiências particulares com os ministros do STF significam que as lideranças indígenas, da mesma forma que os autores da ação popular, conheciam certos costumes do métier. Bourdieu (2001) nomeia de illusio esse conhecimento tácito, não escrito da lógica e das regras do jogo, cuja aquisição pelo sujeito vincula-se à presença naquele universo.

4 Durante a realização da pesquisa que originou o presente artigo foram realizados trabalhos de campo na região da Terra Indígena Raposa Serra do Sol, que objetivaram captar as percepções e estratégias políticas utilizadas pelas populações indígenas na defesa de seus direitos.

5 À época da decisão, o CIR estava sob a coordenação de Joênia Wapichana, primeira mulher indígena advogada do Brasil. Tanto a coordenadora, como a própria organização contaram com a assessoria jurídica dos advogados do Instituto Socioambiental durante todo o processo. 
Levando em conta a impressão de habitualidade fornecida pelo relato, a leitura do trecho acima nos permite perceber que os membros das comitivas indígenas mapeavam o perfil dos ministros do STF de uma maneira sistemática. O repasse das informações de um grupo a outro antes dos encontros permitiulhes identificar os posicionamentos de alguns ministros em relação ao caso.

No dia 19 de março de 2009, na segunda sessão do julgamento, o STF declara constitucional o modelo contínuo da demarcação, derrubando a liminar que garantia a presença dos não-índios naquelas terras. A ação foi julgada parcialmente procedente, nos termos dos fundamentos do voto do Ministro Relator, Carlos Ayres Britto, acrescido pelas condicionantes, ou, nos termos de alguns Ministros, salvaguardas institucionais, elaboradas a partir do voto-vista do Ministro Menezes de Direito. Ainda, a leitura do acórdão nos fornece a extensão do debate realizado, que foram desde o significado do substantivo "índios" na Constituição da República, passando por discussões sobre as terras indígenas como parte essencial do território brasileiro, a velha contenda acerca do falso antagonismo entre a questão indígena, desenvolvimento e meio ambiente, além de questões sobre os direitos originários, as fronteiras, a atuação do exército e a teoria do fato indígena. $\mathrm{Na}$ próxima seção veremos em que medida tais teses, debatidas no caso da Raposa Serra do Sol, alcançaram decisões posteriores ao emblemático caso.

\section{TERRA INDÍGENA PORQUINHOS DOS CANELAS E TERRA INDÍGENA GUYRAROKA}

A escolha dos casos da Terra Indígena Porquinhos dos Canelas e da Terra Indígena Guyraroka não foi aleatória, ao contrário disso, pode-se constatar na análise desses processos que o STF resgatou pontos polêmicos estabelecidos na ocasião do julgamento do caso Raposa Serra do Sol. No primeiro tem-se o resgate da condicionante de número dezessete, que versa sobre a proibição do aumento do território para aquelas comunidades que já passaram pelo procedimento administrativo de demarcação e, no segundo, observa-se a teoria do fato indígena, que estabelece a data da promulgação da Constituição da República de 1988 como marco temporal válido para o reconhecimento de suas terras.

Sobre as condicionantes anexadas à decisão da demarcação da Terra Indígena Raposa Serra do Sol pelo Ministro Menezes de Direito, os argumentos em prol delas ${ }^{6}$ dizem respeito tanto a uma suposta necessidade de esclarecer o

\footnotetext{
6 Após a decisão, foram opostos Embargos de Declaração para esclarecer a extensão da aplicabilidade das condicionantes. No dia 23 de outubro de 2013, o Supremo voltou atrás e decidiu que sua validade seria apenas para a TIRSS, não tendo, portanto, efeito vinculante. De toda sorte, não se pode evitar que a decisão passe a integrar o entendimento daquela Corte sobre a questão indígena, notadamente por não haver reiteradas decisões a esse respeito.
} 
direito do usufruto indígena, como também de operacionalizar a própria decisão a partir do que seria uma "proposição criativa", nos termos utilizados pelo ministro Carlos Ayres Britto (BRASIL, 2008, p. 634). A maioria dos Ministros preferiu considerá-las uma inovação ao invés de inconstitucionais, mesmo que seus termos tenham ultrapassado os limites de discussão delineados pelo pedido inicial dos autores populares, qual seja: a nulidade do processo administrativo que determinou a demarcação contínua da área da Terra Indígena Raposa Serra do Sol. Aqueles que se posicionaram contra anteviram desdobramentos indesejáveis em casos vindouros, posto que a medida tomada pelo Supremo tem significado de uma atividade normativa que, a rigor, coloca em questão os princípios do Estado Democrático de Direito e a separação dos poderes, deixando de lado qualquer discussão com as partes interessadas (art. 5, LIV, CR) ou mesmo com o restante da sociedade.

A condicionante dezessete inviabiliza de forma tácita a correção de eventuais erros ou vícios nas demarcações, sempre que desse ajuste resulte a ampliação de terras. Macula o princípio da imprescritibilidade do direito, além de desconsiderar os esbulhos e violências praticados ainda hoje contra as populações indígenas. Em específico, juridicamente, o apêndice esvazia o disposto no artigo $231 \mathrm{da}$ CR/88, que assegura de forma permanente aos povos indígenas as terras por eles habitadas, bem como aquelas “imprescindíveis à preservação dos recursos ambientais necessários ao seu bem-estar e as necessárias à sua reprodução física e cultural, segundo os seus usos e costumes e tradições".

Por reconhecer que a demarcação da Terra Indígena Porquinhos dos Canelas restou prejudicada pela ocorrência de pressões políticas e vícios no procedimento, a FUNAI constituiu grupo técnico para a realização de novos estudos para a remarcação das terras da etnia Apãnjekra. A primeira demarcação foi iniciada na década de 1970 e homologada pelo Decreto n. 88.599, de 9.8.1983. Os novos estudos realizados confirmaram a legitimidade da reivindicação da população indígena e culminaram com a publicação da Portaria n. 3.508/2009, que determinava que a Terra Indígena passaria de 79.520 ha (setenta e nove mil e quinhentos e vinte hectares) para 301.000 ha (trezentos e um mil hectares). A objeção veio por parte dos municípios de Fernando Falcão, Formosa da Serra Negra e Barra do Corda, todos do estado do Maranhão, que recorreram ao STF por discordarem da ampliação pretendida.O principal argumento dos recorrentes se assentou, exatamente, na condicionante de número dezessete.

É preciso dizer que, inicialmente, os recorrentes ingressaram com mandado de segurança no Superior Tribunal de Justiça. O objetivo era neutralizar os efeitos da Portaria n. 3.508/2009, que reconhecia a ampliação daquele 
território. Não obstante, a Ministra Relatora do processo reconheceu a existência de vícios e irregularidades no processo, como, por exemplo, a ausência de laudo antropológico, entendendo que o procedimento administrativo que deu origem à contestada Portaria tinha por objetivo corrigir os erros do passado, nessa instância se manteve, portanto, a decisão estatal que determinara o alargamento das fronteiras da Terra Indígena.

Inconformados pela derrota no Superior Tribunal de Justiça, os municípios de Fernando Falcão, Formosa da Serra Negra e Barra do Corda recorreram da decisão no STF. Ainda que tenha reconhecido a ausência de força vinculante, em sentido técnico, da decisão da Petição 3.388/RR, do caso Raposa Serra do Sol, o acórdão proferido no Recurso Ordinário proposto pelos municípios maranhenses contra a ampliação da Terra Indígena Porquinhos dos Canelas, deixa clara a ocorrência do que os Ministros do STF consideram a eficácia subjetiva daquela decisão, "especialmente pela força jurídico-constitucional do precedente histórico, cujos fundamentos influenciam direta ou indiretamente na aplicação do direito pelos magistrados em casos semelhantes" (BRASIL, 2014, p. 12). Portanto, a partir desse reconhecimento da eficácia da decisão da Terra Indígena Raposa Serra do Sol, mesmo salientando a inexistência de efeito vinculante, o STF, ancorando-se na condicionante número dezessete, julgou improcedente a ampliação da demarcação Terra Indígena Porquinhos dos Canelas.

Tanto a decisão da Terra Indígena Raposa Serra do Sol, como a da Terra Indígena Porquinhos dos Canelas, consideraram a possibilidade, nos casos de necessidade de ampliação de área já afetada pelo procedimento demarcatório, de o Poder Público se valer de outros instrumentos capazes de satisfazer os anseios das comunidades indígenas. Trata-se da aquisição de novas terras pelos meios tradicionais do direito civil, devidamente resguardadas pelos artigos 32 e 39, III, da Lei 6.001/73. No entanto, não deixa de ser irônico que a desconsideração de vícios nos procedimentos demarcatórios, estabelecidos constitucionalmente e a partir de uma legislação protetiva, especial e específica, possa conduzir as populações indígenas a buscarem a solução desses erros no regramento comum do direito civil, que remonta aos procedimentos correntes de compra e venda no mercado de terras.

A condicionante dezessete foi trazida de forma incidental em um processo no qual a ampliação de terras indígenas não estava em questão. $\mathrm{Na}$ prática, a proibição de aumento na extensão de terras indígenas já demarcadas representou uma atuação normativa do STF. Atuação essa que sequer oportunizou às comunidades indígenas, tanto da Raposa Serra do Sol, como de outras localidades, o direito de contestar a condicionante. Não seria exagero 
afirmar, portanto, que o novo regramento pretende atingir, sem os pressupostos de legitimidade e contrariando o princípio da separação dos poderes, a própria norma constitucional que trata dos direitos dos índios a seus territórios, artigos 231 e 232 da Constituição da República.

O segundo caso selecionado para mapear os efeitos resultantes da decisão da Terra Indígena Raposa Serra do Sol, sobre outros litígios envolvendo demarcação de terras indígenas, vem do Mato Grosso do Sul. O Recurso Ordinário em Mandado de Segurança ${ }^{7}$ foi julgado pelo STF no dia 19 de abril de 2014. Como no caso anterior, o recurso foi interposto contra acórdão proferido pelo Superior Tribunal de Justiça. Igualmente, trata-se de Mandado de Segurança impetrado contra ato do Ministro da Justiça (Portaria 3.219, de 7.10.2009), que reconheceu a posse permanente da Terra Indígena Guyraroka, à etnia Guarani Kaiowá, ao mesmo tempo em que estabeleceu as glebas do recorrente (Avelino Antônio Donatti) como sendo de ocupação tradicional indígena. O STJ decidiu que "a existência de propriedade, devidamente registrada, não inibe a FUNAI de investigar e demarcar terras indígenas". Afirmou ainda que o instrumento legal manejado pelo impetrante não permitia a produção de provas ou mesmo fazer contra prova ao laudo elaborado pela FUNAI.

O laudo da FUNAI atestou que os Guarani Kaiowá tinham a posse da terra até o início da década de 1940 e que as pressões dos fazendeiros locais, bem como as compras de terras, tornaram inviável sua permanência na região. Ainda, conforme informação constante no laudo antropológico e reconhecido pelo STJ, desde meados do século XVIII os Kaiowás encontram-se na região em disputa. Mesmo o desapossamento de suas terras nos anos 1940 por parte dos fazendeiros não impediu que alguns indígenas continuassem na região (invariavelmente trabalhando nas fazendas), mas sem perder a relação tradicional que mantinham com o lugar.

Ao perder a ação no STJ, o recorrente ingressou com recurso no STF. Sob um argumento de natureza processual, o Ministro Relator, Ricardo Lewandowisk, entendeu que a pretensão não poderia ser acolhida, já que não teria respaldo na documentação juntada nos autos. Valeu-se dos precedentes do STF para dizer que apenas a produção de provas poderia contradizer o laudo elaborado pela FUNAI, mas que o instrumento jurídico manejado pelo recorrente (mandado de segurança) não permitia a apreciação adequada do contexto fático-probatório que envolvia o caso, razão pela qual negou provimento ao recurso. Entretanto, sustentando haver um problema de atualização da jurisprudência do STF à luz do decidido no caso da Raposa Serra do Sol e da necessidade de se provar a presença

Recurso Ordinário em Mandado de Segurança nº 29.087. 
indígena no local na data do dia 5 de outubro de 1988, o Ministro Gilmar Mendes pediu vistas do processo.

Ao devolvê-lo para julgamento, o Ministro expressou sua discordância em relação à decisão do STJ argumentando que embora o laudo tenha dito sobre a presença indígena nos anos de 1750-1760, esse fato seria insuficiente para se pretender a demarcação nos novos moldes pretendidos. Na visão do Ministro Gilmar Mendes, "se esse critério pudesse ser adotado, muito provavelmente teríamos de aceitar a demarcação de terras nas áreas onde estão situados os antigos aldeamentos indígenas em grandes cidades do Brasil, especialmente na região Norte e na Amazônia” (BRASIL, 2014, p 23).

O Ministro resgatou o entendimento de terras "tradicionalmente ocupadas" pelos índios, nos termos do art. 231, \ $1^{\circ}$, da Constituição Federal, bem como a Súmula 650, que dispõe que "os incisos I e XI do art. 20 da Constituição Federal não alcançam terras de aldeamentos extintos, ainda que ocupadas por indígenas em passado remoto". De acordo com precedentes do $\mathrm{STF}^{8}$, a palavra tradicionalmente não se refere à posse imemorial, mas à forma de possuir. O que importa, portanto, são as relações de pertencimento estabelecidas entre a comunidade indígena e a terra e não o tempo da ocupação. Essa relação anímica deveria vir acompanhada da presença indígena na localidade à data da promulgação da Constituição da República de 1988. A essa exigência se convencionou chamar de Teoria do Fato indígena.

O Ministro relembrou o decidido no caso Raposa Serra do Sol, cujo "entendimento da Corte então assentado deve servir de apoio moral e persuasivo a todos os casos sobre demarcação de terras indígenas". No julgamento desse caso paradigmático, decidiu-se que a data da promulgação da Constituição é referencial insubstituível do marco temporal para verificação da existência da comunidade indígena e da efetiva e formal ocupação fundiária pelos índios. Ao reavivar a Teoria do Fato indígena, o Ministro Ayres Brito, relator da Petição 3.388/RR, afirmou que ela, a um só tempo, evitaria fraudes em razão da proliferação de comunidades indígenas, coibindo, inclusive, o recrutamento de índios de outras regiões ou países; e também tentativas de descaracterizar a tradicionalidade da posse das suas terras a partir de práticas de violência e expulsão dos índios.

Uma das características que tornou a decisão da Terra Indígena Raposa Serra do Sol paradigmática foi que, nela, discutiu-se a própria substância do direito indígena, deixando de se restringir a questões de natureza processual, em tese, de caráter mais periférico. Em termos práticos, pode-se dizer que a decisão do Supremo reconheceu os direitos daquelas comunidades indígenas sobre o

$8 \quad$ Ministro Nelson Jobim: RE 219.983, julgamento em 9.12.1998. 
seu território. Reconheceu também as práticas de violências e os esbulhos que impediram que à data da promulgação da Constituição da República de 1988 a posse indígena naquela região não estivesse configurada em sua plenitude. Isso significa que, naquele caso, o marco temporal de 1988, que se consolidou no entendimento da Teoria do Fato Indígena, não retirou dos índios o reconhecimento dos seus direitos originários às terras que tradicionalmente ocupam ainda que sejam apresentados títulos de propriedade mais antigos, posto que conquistados à custa dos deslocamentos e das expulsões forçadas sofridas pelos indígenas.

Ancorado na Teoria do Fato Indígena consolidada no interior do processo da Raposa Serra do Sol, o Ministro Gilmar Mendes afirmou a impossibilidade de demarcação da Terra Indígena Guyraroka, utilizando-se do argumento segundo o qual o título de propriedade apresentado pelo recorrente demonstrava a não presença dos Guarani Kaiowá na região desde há setenta anos. O Ministro deu provimento ao recurso ordinário e concedeu a segurança para declarar a nulidade do processo administrativo de demarcação, bem como da Portaria n. 3.219/2009, do Ministro de Estado da Justiça. O voto proferido pelo Ministro Gilmar Mendes coloca em realce as disputas políticas no que tange a interpretação da Teoria do Fato Indígena, uma vez que há na formulação de seu argumento um emprego parcial dessa tese, não considerando, como no caso Raposa Serra do Sol, que a inexistência de indígenas no território na data de promulgação da Constituição é uma decorrência direta de violência, ameaças, grilagens e esbulhos perpetrados contra as populações indígenas. Sobre esse aspecto, o laudo da FUNAI juntado no processo já salientava a existência de continuas e reiteradas expulsões sofridas pela etnia Guarani Kaiowá no transcurso do processo de colonização e de avanço da fronteira de exploração agropecuária.

O voto do Ministro Gilmar Mendes provocou reação imediata do Ministro relator do processo, Ricardo Lewadowski, que tinha decidido pela improcedência do recurso amparando-se na impossibilidade do rito judicial escolhido. O mandado de segurança requer que o litígio não necessite da produção de provas, ademais, o laudo antropológico apresentado pela FUNAI já atestava que a etnia, estava presente na região desde o final do século XVIII e fora expulsa por fazendeiros em meados dos anos 40 do século XX. Entendeu, portanto, o Ministro relator que a decisão do Ministro Gilmar Mendes extrapolava os requisitos exigidos para o manejo de mandado de segurança. De acordo com Lewandowiski, se fosse o caso de se examinar o momento da saída dos índios da terra, essa seria uma matéria a ser decidida em outra via, mas não em mandado de segurança, uma vez que tal instrumento não contempla espaço para o debate e apresentação de novas provas. Assim, a decisão haveria de se ater tão somente à documentação 
já constante no processo administrativo de demarcação conduzido pela FUNAI, aliás, como já havia decidido o STJ. A partir daí, seguiu-se um debate entre os dois Ministros. Embora, a primeira vista possa parecer uma questão de mero formalismo processual, pedimos licença para reproduzirmos integralmente a discussão, por avaliarmos que esse debate esclarece pontos nefrálgicos que perpassam as disputas prático-jurídicas que integram as decisões referentes à demarcação ou ampliação de terras indígenas:

CONFIRMAÇÃO DE VOTO O SENHOR MINISTRO RICARDO LEWANDOWSKI (RELATOR) - Senhor Presidente, quero apenas chamar, respeitosamente, a atenção do douto Colegiado de que se trata de um recurso ordinário em mandado de segurança. O mandado de segurança, como se sabe, exige prova pré-constituída, direito líquido e certo. O acórdão combatido no STJ traz uma ementa e, desta ementa, eu quero destacar apenas dois itens, que são os seguintes: "A ocupação da terra pelos índios transcende ao que se entende pela mera posse da terra, no conceito do direito civil. Deve-se apurar se a área a ser demarcada guarda ligação anímica com a comunidade indígena. Precedente do STF. Pretensão deduzida pelo impetrante que não encontra respaldo na documentação carreada aos autos, sendo necessária a produção de prova para ilidir as constatações levadas a termo em laudo elaborado pela FUNAI, fato que demonstra a inadequação do writ [mandado segurança]. Lá se denegou o mandado de segurança. Eu, analisando com um longo voto todo o alegado neste recurso, acabo por dizer o seguinte: "Como bem observado na decisão impugnada, o exame de todas as alegações expostas na exordial da impetração, bem como nas razões recursais, em face da complexidade da discussão que a permeia, não se revela possível sem apreciação adequada do contexto fático-probatório que envolve a controvérsia, inexequível, todavia, nos estreitos limites do mandamus". Aí eu cito, aqui, uma copiosíssima jurisprudência, inclusive, data venia, do próprio Ministro Gilmar Mendes, em que se assenta isso com toda a clareza. Aqui, por exemplo, eu cito, dentre outros, um voto num mandado de segurança do Ministro Moreira Alves, sempre muito cuidadoso, em que, num trecho da ementa, disse o seguinte: "MANDADO DE SEGURANÇA. DECRETO 94.603, DE 14.7.87, QUE HOMOLOGOU A DEMARCAÇÃO DA ÁREA INDÍGENA PANKARARU. SABER SE AS ÁREAS OCUPADAS PELOS IMPETRANTES SÃO, OU NÃO, TERRAS INDÍGENAS PARA EFEITO DE SUA INCLUSÃO NO DECRETO QUE HOMOLOGOU A DEMARCAÇÃO DA ÁREA INDÍGENA PANKARARU É QUESTÃO DE FATO QUE, POR SER CONTROVERTIDA, NÃO PODE SER DESLINDADA EM MANDADO DE SEGURANÇA. AUSÊNCIA DE DIREITO LIQUIDO E CERTO”. E há um caso muito parecido com esse, que foi julgado, aqui, também, tendo como Relator o Ministro Marco Aurélio, de cuja ementa se extrai o seguinte: “[...] DECRETO HOMOLOGATÓRIO DA DEMARCAÇÃO ADMINISTRATIVA DA ÁREA INDÍGENA 
DENOMINADA “GUASUTI”, NO ESTADO DE MATO GROSSO DO SUL. ALEGADA ILEGALIDADE, POR TRATAR-SE DE TERRAS PARTICULARES, DETIDAS POR PRODUTORES RURAIS, COM BASE EM TÍTULOS DE DOMÍNIO QUE REMONTAM A 1920. CONTROVÉRSIA CUJA DILUCIDAÇÃO IMPLICA A NECESSIDADE DE APURAR-SE, CONQUANTO DESOCUPADAS PELOS ÍNDIOS HÁ CERCA DE 50 ANOS, COMO ALEGADO, AS TERRAS EM QUESTÃO, EM ALGUMA ÉPOCA, TERIAM SAÍDO DO DOMÍNIO DA UNIÃO, CIRCUNSTÂNCIA SEM A QUAL NÃO SE PODERIA RECONHECER LEGITIMIDADE A ALIENAÇÃO QUE, SEGUNDO SE ALEGA, DELAS FEZ O ESTADO-MEMBRO [...]". Então, o Ministro Marco Aurélio, que é extremamente cuidadoso em matéria de desapropriações para efeito de reforma agrária e, também, para efeitos de terras indígenas, ele, aqui, com muita precisão, num caso, exatamente idêntico a esse. Trago outra jurisprudência, aqui, em que se mostra que o precedente da Raposa Serra do Sol não pode ser estendido para além daquele caso, não tem nenhum efeito vinculante. De maneira que, para examinar se os índios saíram, ou não, há muito tempo da terra, isto é matéria a ser decidida nas vias ordinárias, nas vias apropriadas, mas não em mandado de segurança - como bem decidiu o STJ - e, muito menos, em recurso ordinário, em que se não aduz nenhuma prova nova, como não poderia, aliás, aduzir. Mas, discute-se, simplesmente, matéria já repisada no processo expropriatório. Mantenho meu ponto de vista, data venia, em que pese o brilhante voto do Ministro Gilmar Mendes. Estou negando provimento ao recurso ordinário e julgando prejudicado o pedido de medida liminar. Essa é uma questão muito séria, realmente, para se decidir em mandado de segurança. A Constituição, com todas as letras, no art. 231, reconhece a posse das terras tradicionalmente ocupadas pelos índios; e o $\int 4^{\circ}$ diz o seguinte: "\$ $4^{\circ}$-As terras de que trata este artigo são inalienáveis e indisponíveis, e os direitos sobre elas, imprescritíveis". É uma expressão que o constituinte usa, um conjunto de palavras das mais fortes no texto constitucional como um todo. Nós sabemos que o que está havendo, hoje, em todo o Brasil, lamentavelmente, é um novo genocídio de indígenas, em várias partes do país, em que os fazendeiros, criminosamente, ocupam terras que eram dos índios, e posse dos índios, os expulsam manu militari, e depois os expedientes jurídicos, os mais diversos - depois de esgotados os expedientes, evidentemente, ilegais e até criminosos -, acabam postergando o cumprimento desse importante dispositivo constitucional. Apenas essas breves considerações que faço, até com bastante ênfase, para reforçar o meu ponto de vista.

CONFIRMAÇÃO DE VOTO O SENHOR MINISTRO GILMAR MENDES - Presidente, só para deixar claro as questões que foram agora pontuadas. Em primeiro lugar, o precedente de Raposa Serra do Sol não se dirige apenas ao caso de Raposa Serra do Sol. Basta ler os enunciados para saber que muitos deles não se aplicam à Raposa Serra do Sol, até porque já estava realizado. Na verdade, o Tribunal, ali, modulou os efeitos para não anular aquela demarcação, tendo em vista as suas implicações, 
mas quis dizer, por exemplo, não se pode fazer demarcação sem a participação de estados e municípios, porque aquilo era um caso surreal em que a área inteira do município foi colocada dentro da demarcação da área demarcada -, acabando com uma unidade toda. Então, o que se assentou em Raposa Serra do Sol? Que nas novas demarcações - claro, é para as novas demarcações - tem que haver a presença, no processo demarcatório, de estados e municípios. Isso, claro, não se aplica ao caso de Raposa Serra do Sol, até porque o Tribunal não quis conceder a ordem naquele caso, não quis anular, em função da repercussão que isso teria e dos inconvenientes.

O SENHOR MINISTRO RICARDO LEWANDOWSKI (RELATOR) Vossa Excelência me permite uma questão?

O SENHOR MINISTRO GILMAR MENDES - Sim.

O SENHOR MINISTRO RICARDO LEWANDOWSKI (RELATOR) - A Raposa Serra do Sol era um caso atípico, em que lá se reivindicava, praticamente, dois terços de um Estado-membro da Federação brasileira.

O SENHOR MINISTRO GILMAR MENDES - Exatamente.

O SENHOR MINISTRO RICARDO LEWANDOWSKI (RELATOR) - Agora, eu pergunto - e faço uma pergunta retórica: será que no caso de uma fazenda de pequeno, médio, ou até grande porte, o município e o estado devem ser chamados como litisconsortes? Data venia, penso que é uma demasia, com todo o respeito.

O SENHOR MINISTRO GILMAR MENDES - No caso de Mato Grosso do Sul é exatamente essa conflagração que existe, em função de se estar fazendo demarcação de áreas altamente produtivas. Então, por isso que a questão se coloca. Claro, Copacabana certamente teve índios, em algum momento; a Avenida Atlântica certamente foi povoada de índio. Adotar a tese que está aqui posta nesse parecer, podemos resgatar esses apartamentos de Copacabana, sem dúvida nenhuma, porque certamente, em algum momento, vai ter-se a posse indígena. Por isso que o Tribunal fixou o critério, inclusive em relação aos aldeamentos extintos que pegariam uma boa parte de São Paulo. Hoje, um dos maiores municípios, e talvez um dos maiores orçamentos e dos maiores PIBs, é o de Guarulhos. Então se esse argumento pudesse presidir, tivesse valia, certamente nós teríamos que voltar, e isso contraria, inclusive, a Súmula do Supremo sobre os aldeamentos extintos. Esse é um ponto importante. Agora, vamos dizer que, não obstante a área deva ser concedida aos índios ou a área dos índios, já concedida, deva ser expandida, porque é a questão do conflito no Mato Grosso do Sul. Neste caso, faz-se o caminho da desapropriação, foi o que foi dito em Raposa Serra do Sol. Agora, de longe, as hipóteses de Raposa Serra do Sol, claro, nós dissemos: tecnicamente era um processo de caráter concreto, era uma ação popular, logo não teria efeito, mas isso não teria efeito "vinculante". 
O SENHOR MINISTRO RICARDO LEWANDOWSKI (RELATOR) Foi o que eu disse: vinculante.

O SENHOR MINISTRO GILMAR MENDES - Mas, não significa que nós fizemos lá uma boutade, que estivéssemos brincando ao julgar aquilo; até porque, o que nós dissemos? A União não pode amanhã retirar territórios a seu bel talante, e nós sabemos como isso é feito, esses laudos, laudo da FUNAI. E, veja, agora quanto à técnica, laudo da FUNAI dizendo que houve índio em algum momento, e isso é suficiente para retirar cidades inteiras de um dado local. Veja o risco que isso envolve para todos, quer dizer, infelicitando inclusive os índios que vão ser, na verdade, não sujeitos, mas objeto desse tipo de insegurança. E mais: nós estamos julgando só com base nos dados postos nos autos. É mandado de segurança, sim; mas nós estamos julgando com base nos dados postos nos autos. O que é? Uma demarcação depois do nosso julgamento, portanto sob essa diretriz. E nós estamos julgando com base nos dados que já, a priori , atestam que a comunidade indígena já não estaria lá há mais de 70 anos. O próprio título; esses são os dados, e esses dados são insuprimíveis, são inquestionáveis, dados assumidos pelo próprio STJ.

O SENHOR MINISTRO RICARDO LEWANDOWSKI (RELATOR) Desculpe. Não, da ementa aqui do STJ, diz o seguinte: pretensão deduzida pelo impetrante que não encontra respaldo na documentação carreada aos autos.

O SENHOR MINISTRO GILMAR MENDES - Não. Mas, a documentação probatória é a do laudo.

O SENHOR MINISTRO RICARDO LEWANDOWSKI (RELATOR)

- Mas nós nos valemos do acórdão. Se o acórdão diz que a pretensão não tem respaldo...

O SENHOR MINISTRO GILMAR MENDES - Não. O acórdão está calcado no laudo da FUNAI, e o laudo da FUNAI diz que há mais de 70 anos não havia famílias indígenas.

O SENHOR MINISTRO RICARDO LEWANDOWSKI (RELATOR) Mas são terras tradicionais, a Constituição assim o diz.

O SENHOR MINISTRO GILMAR MENDES - Terra tradicional é Copacabana, terra tradicional é Guarulhos.

O SENHOR MINISTRO RICARDO LEWANDOWSKI (RELATOR) Bem, mas Copacabana não chamou a atenção da ONU, e Mato Grosso do Sul chamou, interessante isso, não é?

O SENHOR MINISTRO GILMAR MENDES - Agora, a ONU é o argumento para o quê?

O SENHOR MINISTRO RICARDO LEWANDOWSKI (RELATOR) Não, Copacabana é o argumento para o quê?

O SENHOR MINISTRO GILMAR MENDES - É a posse tradicional. 
O SENHOR MINISTRO RICARDO LEWANDOWSKI (RELATOR) Para mostrar um argumento ad absurdum? Isso é o que estou dizendo, é como a questão das terras quilombolas, há de se fazer a devida distinção. Eu ouvi dizer que existem quilombolas que reivindicam as terras lá da Lagoa, onde existem condomínios de luxo, é claro que modus in rebus [há um limite nas coisas].

O SENHOR MINISTRO GILMAR MENDES - A solução jurídica está na desapropriação, segundo os parâmetros. Agora, os dados que estão no acórdão são claramente dados de que não havia posse indígena há mais de 70 anos, e para isso o próprio acórdão do STJ diz que alguns índios continuaram, com base no laudo da FUNAI, a prestar serviço como peões.

O SENHOR MINISTRO RICARDO LEWANDOWSKI (RELATOR) - Mas, o agronegócio quer isso mesmo: expulsa os índios e depois os contrata como boias-frias. É assim que está acontecendo no Brasil todo.

O SENHOR MINISTRO GILMAR MENDES - Recentemente, Ministro, nós encontramos índios aqui em Brasília reivindicando a área do Noroeste. Certamente, nós que moramos em Brasília há muitos anos sabemos que não tinha índio em Brasília desde pelo menos a fundação, mas, se retornarmos no tempo, vamos achar, como em outras áreas do Brasil todo. Agora, recentemente houve uma discussão sobre índios no Noroeste, em função de um bairro que estava sendo criado. Certamente, vamos encontrar índios na construção civil, nas atividades de futebol, nas atividades industriais, nem por isso se diz que eles, na origem, estavam naquele local. Ora, então a questão posta no mandado de segurança, e é própria do mandado de segurança, porque as provas estão préconstituídas, por isso que entendo que, no caso, segundo os parâmetros que nós estabelecemos, não havia posse indígena em 5 de outubro. Isso segundo o próprio laudo da FUNAI que lastreia, depois, a portaria, e que lastreia também a decisão do STJ. Por isso que estou dando provimento ao recurso.

Com votação majoritária o STF deu provimento ao recurso ordinário e concedeu a segurança para declarar a nulidade do processo administrativo da demarcação da Terra Indígena Guyraroka, bem como da Portaria n. 3.219/2009, nos termos do voto do Ministro Gilmar Mendes. O Ministro ainda afirmou que o procedimento específico da desapropriação por interesse social ou por utilidade pública, deveria ser seguido, com o pagamento de justa e prévia indenização ao seu proprietário, caso a União considerasse a necessidade de terras para as populações indígenas.

O debate entre os ministros espelha o que argumentávamos sobre a relevância de contextos extraconstitucionais para a formação de sensibilidades que orientam as decisões judiciais. As justificativas jurídicas manejadas no caso da Terra Indígena Raposa Serra do Sol que alcançaram as decisões proferidas depois 
desta, mostram o peso da força política nas decisões de determinados processos. Observamos o que Atienza (2002) chamou de argumentos consequencialistas a orientarem com relativa presteza a atuação decisória dos julgadores. A utilização de argumentos dessa natureza com vistas a orientar a tomada de suas decisões nos leva a questionar a atuação da Corte Superior brasileira no que diz respeito à efetiva proteção dos direitos indígenas quando lhes é dada a oportunidade para decidir a favor dessa minoria, vez que "não decidem apenas conforme as regras formais do ordenamento jurídico" (DA ROS, 2007, p.96).

O caso da Terra Indígena Guyraroka nos permite pensar em uma teoria da prática jurídica. A recomendação de Bourdieu (1989) de tomar a própria ciência do direito como objeto nos faz perceber que mesmo interpretações de cunho processual podem ser utilizadas para criar obstáculos quando da efetividade dos direitos indígenas. Nesse sentido, impõe-se "o afastamento das ideias de neutralidade e de universalidade também em relação aos instrumentos que a priori são apresentados como sendo de natureza puramente formal, nos quais estariam inscritos esquemas legítimos de interpretação e aplicação do direito" (SHIRAISHI NETO, 2007, p.125). Trata-se do monopólio de um formalismo que na verdade sinaliza um poder invisível de controle social, que reveste de técnica jurídica um debate essencialmente político. A partir dessa análise e ao modo do que nos sugere Bourdieu (2014), trata-se de dar corpo a um projeto de universalizar as condições de acesso ao universal, escapando, portanto, a essa cultura que aparentemente une, mas, na verdade, divide.

\section{CONSIDERAÇÕES FINAIS}

Ao longo dos debates orientadores da decisão proferida no âmbito da Petição 3.388/RR não foram raras as afirmações que exaltavam as possibilidades de se replicar os seus termos, material ou substantivamente, a outros casos de demarcação de terras indígenas que porventura fossem levados ao Tribunal. Por essa razão, não é estranho encontrar nas decisões subsequentes à Raposa, argumentos que sustentam sua precedência jurisprudencial.

Além da chamada "força moral subjetiva" a que se referem alguns Ministros em relação aos desdobramentos da decisão da Raposa Serra do Sol, também é preciso ter à vista suas implicações formais em relação à demarcação de territórios indígenas. A tentativa da Advocacia-Geral da União de fixar, por meio da Portaria 303, um entendimento argumentativo com base nas condicionantes do caso Terra Indígena Raposa Serra do Sol, bem como o recrudescimento para a aprovação do Projeto de Emenda Constitucional (PEC) 215-A de 2000, que 
pretende alterar o artigo 231 da CR/88, transferindo do governo federal para o Congresso Nacional a atribuição de aprovar a demarcação, além da necessidade de ratificar as terras já homologadas (BRASIL, 2000), mostram um desejo de se deslocar a demarcação do campo do direito para uma arena política, em geral instável e desfavorável.

\section{REFERÊNCIAS BIBLIOGRÁFICAS}

ARENDT, H. As Origens do Totalitarismo. Trad. Roberto Raposo. Rio de Janeiro: Forense, 1979.

ATIENZA, M. As razões do argumento: teorias da argumentação jurídica. São Paulo: Landy, 2002.

BOURDIEU, P. O Poder Simbólico. Rio de Janeiro: Bertrand Brasil, 1989.

Meditações Pascalianas. Rio de Janeiro: Bertrand Brasil, 2001.

Sobre o Estado. São Paulo: Companhia das Letras. 2014.

BRASIL. Supremo Tribunal Federal. Súmula n. 650 do STF, de 24 de setembro de 2003. Dispõe sobre Bens da União. Brasília, 2003. Disponível em: http://www.dji.com.br/normas_ inferiores/regimento_interno_e_sumula_stf/stf_0650.htm. Acesso em: 15 jun. 2012.

BRASIL. Supremo Tribunal Federal. Petição n. ${ }^{\circ}$ 3388/RR. Relator Ministro Carlos Ayres Britto. Brasília: TSF, 2008. Disponível em: http://www.stf.jus.br/portal/principal/ principal.asp. Acesso em: 11 mar. 2010.

BRASIL. Câmara dos Deputados. Comissão Especial destinada a apreciar e proferir parecer à Proposta de Emenda à Constituição no 215-A, de 2000. Disponível em: http:// www.camara.gov.br/proposicoesWeb/prop_mostrarintegra; jsessionid=71D9A6B18F95C 303F0C816F4CB491918.node1 ? codteor $=1076126 \&$ filename $=$ Tramitaca PEC+215/2000. Acesso em: 22 ag. 2013.

BRASIL. Supremo Tribunal Federal. Recurso Ordinário em Mandado de Segurança.n. 29.542 . 2014. Disponível em: http://redir.stf.jus.br/paginadorpub/paginador.jsp? docTP=TP\&docID=6937880. Acesso em 25 de março de 2015.

BRASIL. Supremo Tribunal Federal. Recurso Ordinário em Mandado de Segurança.n. 29.087. 2014. Disponível em: http://redir.stf.jus.br/paginadorpub/paginador.jsp? docTP=TP\&docID=7218303 Acesso em 25 de março de 2015.

CARRIÓ, G. R. Notas sobre derecho y lenguaje. Buenos Aires: Abeledo-Perrot, 1986. CARVALHO, J. B.; MAIOR, A. P. S. Requerimento para serem incluídos na Petição 3388 como Litisconsórcios Ativos. 2008. Disponível em http://www.socioambiental.org/ inst/esp/raposa/?q=documentos. Acesso em: 10 mar. 2011. 
COMPROMISSO COM OS POVOS INDÍGENAS DO BRASIL. Disponível em: http://www. construindoumnovobrasil.com.br/images/downloads/compromisso comospovosindigenas.pdf. 2002. Acesso em: 22 mar. 2013.

COSTA SILVA, M. I. Raposa Serra do Sol: agentes políticos, conflitos e interesses. Tese de doutorado. UNICAMP, Campinas, 2012.

DA ROS, L. Tribunais como árbitros ou como instrumentos de oposição: uma tipologia a partir dos estudos recentes sobre judicialização da política com aplicação ao caso brasileiro contemporâneo. Direito, Estado e Sociedade. n. 31, Rio de Janeiro, 2007.

DUARTE DO PATEO, R. A Demarcação de Terras Indígenas no Brasil e o Caso Raposa Serra do Sol. In: MIRAS, Julia Trujillo et al. (org.). Makunaíma Grita! Terra Indígena Raposa Serra do Sol e os Direitos Constitucionais no Brasil. Rio de Janeiro: Beco do Azougue, 2009.

LASSALLE, F. A essência da constituição. Rio de Janeiro: Lumem Juris, 2001.

LIMA, A. C. de S. Um olhar sobre a presença das populações nativas na invenção do Brasil. In: SILVA, Aracy Lopez da; GRUPIONI, Luiz Donisetti Benzi (org.). A Questão Indígena na Sala de Aula: novos subsídios para professores de $1^{\circ}$ e $2^{\circ}$ graus. Brasília: MEC, 1995.

SILVA, M. A Demarcação de Terras Indígenas no Brasil e o Caso Raposa Serra do Sol. In: MIRAS, Julia Trujillo et al. (org.). Makunaíma Grita! Terra Indígena Raposa Serra do Sol e os Direitos Constitucionais no Brasil. Rio de Janeiro: Beco do Azougue, 2009.

REPOLÊS, M. F. S. O Papel Político do STF e a Hermenêutica Constitucional: considerações a partir da teoria, da cultura institucional e da jurisprudência. Jus Navigandi, Teresina, ano 8, n. 150, 3 dez. 2003. Disponível em: http://jus.uol.com.br/ revista/texto/4570. Acesso em: 8 fev. 2011.

SHIRAISHI NETO, J. O Campo Jurídico em Pierre Bourdieu: a produção de uma verdade a partir da noção de propriedade privada nos manuais de Direito. 2007. Disponível em: http://www.uff.br/ppgsd/confluencias/revista_confluencias_vol_02. pdf. Acesso em: 15 ago. 2007.

VIEIRA, O. V. Supremo Tribunal Federal: jurisprudência política. São Paulo: Malheiros, 2002.

YAMADA, É. M.; VILLARES, L. F. Julgamento da Terra Indígena Raposa Serra Do Sol: todo dia era dia de índio. Revista de Direito GV, São Paulo, n. 6, p. 143-158, jan./jun 2010.

WEINGAST, B. R. The Political Foundations of Democracy and the Rule of Law. The American Political Science Review, Vol. 91, No. 2 (Jun., 1997), pp. 245-263.

WERNECK VIANNA, L.; CARVALHO, M. A. R. de; MELO, M. P. C.; BURGOS, M. B. A judicialização da política e das relações sociais no Brasil. Rio de Janeiro: Revan, 1999. 